\title{
Seminoma testicular bilateral sincrónico en un paciente adulto con criptorquidia bilateral: reporte de un caso y revisión de la literatura
}

\section{Synchronous bilateral testicular seminoma in an adult patient with bilateral cryptorchidism: A case report and literature review}

\section{Sr. Director:}

El cáncer de testículo representa el proceso maligno más frecuente en varones entre 15 a 35 años de edad ${ }^{1}$, siendo a su vez una de las neoplasias con mayor tasa de curación y en las que se cuenta con un mayor arsenal terapéutico. De estas neoplasias el tumor germinal representa el $95 \%{ }^{2}$, siendo bilaterales en 1-4\% de los casos y se presenta de forma sincrónica en menos del $25 \%{ }^{3}$, por lo que se considera a estos últimos como entidades muy raras, motivo por el cual presentamos el siguiente caso.

Se trata de un paciente de 44 años de edad con antecedente de síndrome de Down y criptorquidia bilateral no tratada, que consulta por un cuadro de tres días de evolución con aumento de volumen en la región inguinal izquierda, asintomático, que fue observado por sus familiares.

En la exploración física se observa un aumento de volumen en la región inguinal izquierda, doloroso al tacto, de consistencia pétrea, no fijo, móvil, eutérmico, con bolsa escrotal hipotrófica y vacía.

Por medio del ultrasonido inguino-escrotal se observa una masa inguinal izquierda a expensas de testículo izquierdo de 99 cc de volumen, heterogénea, con múltiples calcificaciones puntiformes (fig. 1) y testículo derecho ausente.

En la tomografía axial computarizada (TAC) de abdomen no hay adenopatías retroperitoneales; se observa una masa en el hueco pélvico del lado derecho que desplaza la vejiga a la izquierda, de $10 \times 15 \mathrm{~cm}$, con componente quístico en el centro, además de la presencia de una masa a nivel inguinal izquierdo, con diámetro mayor de $10 \mathrm{~cm}$, de componente sólido (fig. 2).

La TAC de tórax no mostró alteraciones.

Deshidrogenasa láctica (DHL) 601, alfafetoproteína 5,08 y fracción beta de gonadotropina coriónica humana 11,8.

Se establece tratamiento quirúrgico, sometiendo al paciente a orquiectomía radical izquierda y laparotomía exploradora para la búsqueda y extracción del testículo derecho. En el testículo derecho encontramos un seminoma clásico invadiendo la rete testis y el izquierdo infiltrando la túnica albugínea, con invasión angiolinfática. El estadio clínico del testículo derecho fue T1 N0 M0 S2 y el del izquierdo T2 N0 M0 S2.

Dentro de las neoplasias que afectan al varón joven el cáncer testicular es el tumor sólido maligno más común; a pesar de esto en nuestros días sigue siendo una enfermedad maligna potencialmente curable. Dentro de la forma de presentación de los casos con afección bilateral tenemos dos tipos: la sincrónica (afección simultánea de ambos testículos en el momento del diagnóstico) y metacrónica (existe un periodo de tiempo entre la presentación del primer tumor y la aparición del segundo). Ambas formas de presentación difieren en cuanto a su incidencia y a la variedad histológica predominante.

La aparición de un tumor testicular bilateral primario es rara; su prevalencia oscila entre el 2,5 y el $5 \%$, siendo en su mayoría metacrónicos ${ }^{2}$. Se reportan alrededor del 10\% de casos de sincrónicos, y estos son del mismo tipo histológico, siendo en un $80 \%$ seminomas, como el caso que presentamos. El $20 \%$ restante se han identificado como teratomas

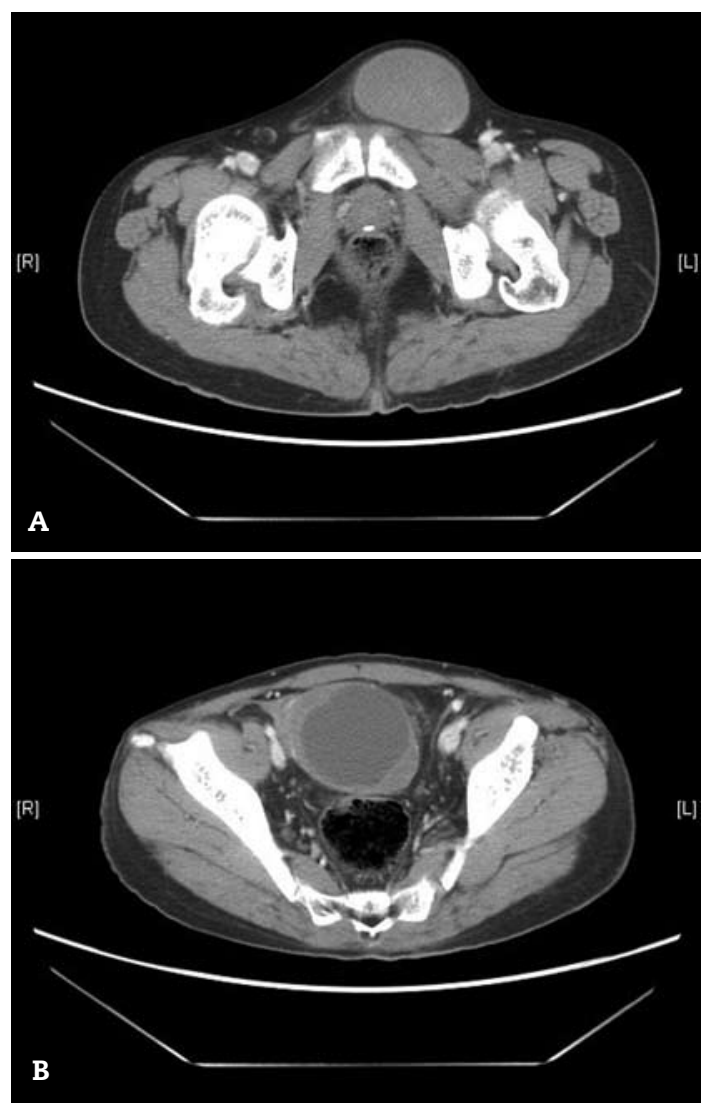

Figura 1 - A: Imagen de tomografía axial en la que se observa la presencia de masa a nivel inguinal izquierdo, compatible con testículo a ese nivel. B: Nótese la presencia de masa al nivel de la cavidad pélvica. 
mixtos, tumor del saco vitelino y carcinomas embrionarios (puros o combinados) ${ }^{3-5}$.

El pronóstico de estos tumores no es peor que el de los unilaterales; en ambos depende del estadio clínico en el momento del diagnóstico ${ }^{3,6}$.

Existen dos estudios donde se analizan 7 y 6 casos clínicos y se cree que los tumores bilaterales sincrónicos pueden presentarse en estadios elevados, aunque debido al reducido número de pacientes incluidos en este estudio los resultados no pueden ser del todo concluyentes $3,4,7$.

El tratamiento quirúrgico (orquiectomía bilateral) sigue siendo el procedimiento definitivo para el adecuado diagnóstico histopatológico y tratamiento local de esta patología ${ }^{6}$. Desafortunadamente esta conducta terapéutica genera importantes trastornos endocrinos y psicológicos, por lo que se llega a mencionar una alternativa terapéutica que consiste en orquiectomía conservadora, realizada más frecuentemente en el centro y norte de Europa. Esta técnica está recomendada sobre todo en tumores de dimensión menor o igual a $2,5 \mathrm{~cm}$, y se han comunicado resultados satisfactorios en cuanto a curación y calidad de vida ${ }^{8-11}$.

Sabemos que una parte fundamental del manejo en estos pacientes es la quimioterapia, y con la introducción de cisplatino a esta batería de medicamentos la tasa de supervivencia de los pacientes con cáncer testicular llega a superar el $90 \%$, aunque aumenta el riesgo de presentar una segunda neoplasia testicular en forma metacrónica ${ }^{2,3,12}$.

La afección bilateral no implica necesariamente un peor pronóstico comparado con los casos de afección unilateral, ya que se ha reportado una curación superior al $90 \%{ }^{1}$.

La afección bilateral del cáncer testicular sigue siendo una forma de presentación poco frecuente en esta patología, con una incidencia alrededor del 1,5\% de los casos, y de estos la forma sincrónica es aún más rara (por debajo del $20 \%$ de los casos de bilateralidad). La asociación entre criptorquidia y tumor testicular bilateral es todavía objeto de controversia, existiendo series que indican una mayor frecuencia, mientras que en otras la frecuencia es semejante a la de los casos de tumor unilateral. El tratamiento en general de los casos de bilateralidad no difiere significativamente del unilateral, e incluso en casos seleccionados puede intentarse la cirugía preservadora del testículo.

\section{B I B L I O G R A F Í A}

1. Martínez MR, Hernández GF, Rodolfo JD, Lozano JF, Sánchez GA. Seminoma testicular bilateral sincrónico en un paciente adulto con criptorquidia bilateral. Rev Mex Urol. 2003;63(4):157-61.

2. Diz Rodríguez R, Virseda Chamorro M, Arce Gil I, Saenz Benito D, Alpuente Román C, Paños Lozano P. Tumores bilaterales de testículo. Actas Urol Esp. 2007;31(3):250-2.


Figura 2 - Muestra quirúrgica de testículo izquierdo (A) y derecho (B).

3. Soto delgado M, Pedrero Márquez G, Ramírez Chamorro F, Rodríguez-Rubio Cortadellas F, Sánchez Bernal C, González Moreno D. Neoplasia testicular bilateral sincrónica. Presentación de un nuevo caso clínico. Arch Esp Urol. 2007;31(1):58-60.

4. Bulent A, Taner DR, Tolga T, Sertac Y, Celik T, Ferruh Z, et al. Bilateral testicular germ cell tumors in Turkey: Increase in incidence in last decade and evaluation of risk factor in 30 patiens. J Urol. 2007;178:129-33.

5. Coli A, Bigotti G, Dell'Isola C, Castri F, Rulli F, Massi G. Synchronous bilateral testicular germ cell tumors with different histology. Case report and review of the literature. Urol Int. 2003;71(4):412-7.

6. Coogan CL, Foster RS, Simmons GR, Tognoni PG, Roth BJ, Donohue JP. Bilateral testicular testicular tumors and management and outcomes in 21 patients. Cancer. 1998;83(3):547-52.

7. Cañis Sánchez A, Conde Santos G, Alonso García N, León Morales E, Arango Toro O, Gelabert Mas A. Actitud diagnóstica y terapéutica en el tumor germinal bilateral. Presentación de un caso y revisión de la literatura. Actas Urol Esp. 2003;27(2):147-51.

8. Schmitz A. Bilateral and synchronic seminomatous testicular neoplasia. Int Baz J Urol. 2003;29(4):330-1.

9. Mearini E, Bracarda S, Crino L, Zicchi A, Porena M. Conservative surgery and quality of life in a young patient with synchronous bilateral embryonal carcinoma. Eur Urol. 1996;29(1):119-21.

10. Theodore $\mathrm{CH}$, Terrier-Lacombe MJ, Laplanche A, Benoit G, Fizazi K, Stamerra O, et al. Bilateral germ -cell tumors: 22 years of experience at the Institut Gustave Roussy. Br J Cancer. 2004;90(1):55-9.

\section{A. García Morúa*, J. D. Gutiérrez García, E. Ortiz Lara Gerardo, R. Martínez Montelongo y S. Gómez Guerra Lauro} Hospital Universitario Dr. José E González, Monterrey NL, México

$H^{*}$ Autor para correspondencia Correo electrónico: agmorua@hotmail.com; Alejandro.garcia@ urologiahu.org.mx (A. García Morúa) 